\title{
Producciones artesanales, construcción identitaria y dinámica de poder en poblaciones mapuches de Neuquén (Argentina)
}

\section{Handcrafts productions, identity construction and power dynamics in mapuche communities in Neuquen (Argentina)}

\author{
Mónica B. ROTMAN \\ Universidad de Buenos Aires \\ Consejo Nacional de Investigaciones Científicas y Técnicas (CONICET) \\ mobea@fibertel.com.ar
}

Recibido: 17 de mayo de 2010

Aceptado: 24 de junio de 2010

\begin{abstract}
Resumen
Abordamos en este artículo determinados procesos productivos artesanales de comunidades mapuches de la Provincia de Neuquén (Argentina), haciendo una referencia también a la instancia de la comercialización, considerando la actividad en su doble y fluctuante dimensión simbólica y económica y en vinculación con procesos de construcción identitaria étnica. Planteamos las condiciones contextuales en las cuales se inscribe la existencia de las agrupaciones y algunas características generales — demográficas, jurídicas, económicasque refieren a su situación actual. Analizamos luego el ámbito artesanal, examinando sus particularidades y su dinámica, entendiendo que éste se ha instituido en uno de los espacios donde se dirime la conformación y legitimación de la identidad étnica de los productores mapuches. Damos cuenta asimismo de la intervención de agencias estatales e instituciones no gubernamentales en tales procesos, entendiendo que los mismos se inscriben en un marco de relaciones interétnicas signadas por una asimetría histórica.
\end{abstract}

Palabras clave: Producciones artesanales, Poblaciones mapuches de Neuquén, Identidad étnica.

\begin{abstract}
In this article we deal with certain handcrafts production processes of the mapuche communities in the Province of Neuquen, Argentina, making reference to an instance of commercialization, taking into consideration such activity in its double changing symbolic and economic dimension, and in connection with the processes of ethnic identity construction. We firstly present the contextual conditions in which the existence of these groups is inscribed, as well as general characteristics — such as demographical, legal, economic - that refer to the situation of these communities at present. We then analyze the handcrafts production process, examining the special features and dynamics of such, considering that this field has been instituted in one of the spaces where the conformation and legitimacy of the ethnic identity of mapuche producers is discussed. Furthermore, we explain the intervention of state agencies
\end{abstract}


and non-governmental institutions in these processes, understanding that such are inscribed in a frame of inter-ethnic relationships marked by a historical asymmetry.

Keywords: Handcrafts productions, Mapuche populations from Neuquen, Ethnic identity.

Referencia normalizada: Rotman, M. B. (2011). Producciones artesanales, construcción identitaria y dinámica de poder en poblaciones mapuches de Neuquén (Argentina). Revista de Antropología Social, 20, 347-371.

SUMARIO: 1. Introducción. 2. Contextos y condicionamientos. 3. Las comunidades. 3. 1. Actividades económicas. 4. Las actividades artesanales. 4. 1. Los tejidos de Chiquilihuín. 4. 2. Las piezas en madera de Aucapán. 5. Las instancias de la comercialización. 6. Consideraciones finales. 7. Referencias bibliográficas.

\section{Introducción}

La producción artesanal de los pueblos originarios ha sido considerada históricamente como expresión identitaria privilegiada de ellos. Interesa reflexionar en este trabajo sobre tal atribución en la actualidad, situando la actividad en el marco de las condiciones estructurales y contextuales que afectan a las poblaciones indígenas y considerando la doble y fluctuante dimensión simbólica y económica que caracteriza las producciones artesanales.

Hoy día, para las comunidades mapuches de Neuquén, el ámbito artesanal se ha instituido en uno de los espacios donde se dirime la conformación y legitimación de la identidad étnica de sus productores.

Analizamos en este trabajo las instancias productivas y de comercialización artesanal, ámbitos donde se desarrollan procesos de construcción identitaria étnica, en las comunidades Chiuquiliuín y Aucapán, situadas en el sur de la Provincia de Neuquén, en Patagonia, Argentina ${ }^{1}$.

\section{Contextos y condicionamientos}

Las agrupaciones de Chiuquilihuín y Aucapán se ubican en el Departamento de Huiliches, al sudoeste de la Provincia de Neuquén. Situadas a 54 y 60 km. de Junin de los Andes, ciudad cabecera del Departamento, se accede a ellas por las rutas provinciales 23 y 60 - esta última vía comunica Argentina con Chile a través del paso internacional Tromen-.

En un contexto general, se da en la actualidad un auge del turismo a nivel regional, perfilándose éste como actividad económica sumamente relevante para el área,

${ }^{1}$ En la actualidad, el pueblo mapuche reside además en las provincias de Río Negro, Chubut, Santa Cruz, Tierra del Fuego, La Pampa y Buenos Aires. Según datos de la Encuesta Complementaria de Pueblos Indígenas (ECPI, 2004-2005), adicional al Censo de Población 2001 (INDEC, 2001), el total de habitantes que se reconoce perteneciente y/o descendiente en primera generación del pueblo mapuche en todo el país es de 113.680 y en las cuatro provincias iniciales es de 76.606 personas. Por su lado, la Coordinadora de Organizaciones Mapuches de Neuquén estimaba en el año 2003, para esta provincia exclusivamente, 65.000 pobladores pertenecientes a dicha etnia. 
que abarca diversas localidades de Patagonia con atractivos naturales, paisajísticos, culturales e históricos ${ }^{2}$.

Las Comunidades de Chiuquilihuín y Aucapán ${ }^{3}$, si bien se asientan en una zona donde los atractivos vinculados con los paisajes son menores respecto de otros sitios que conforman el denominado corredor de los lagos — andino-patagónicos ${ }^{4}$-, constituyen un área en la cual el turismo es incentivado tanto desde instancias gubernamentales como privadas.

En el contexto provincial y respecto a la actividad turística, el "Plan Maestro de Turismo", que fija la política del estado neuquino sobre ella para el periodo 20032007, define 43 productos de interés, entre los que figuran las "artesanías" y el "turismo en comunidades mapuche" (http://www.neuquentur.gov.ar, 2008).

A nivel de la ciudad cabecera del departamento y en concordancia con políticas regionales y provinciales, algunos indicadores muestran el crecimiento de la actividad turística. Asimismo, Junín de los Andes también atrae visitantes a la zona al ocupar un lugar destacado en el marco del denominado "turismo religioso", una modalidad sumamente promocionada por la provincia.

En el contexto provincial, cabe marcar ciertas particularidades político-económicas que caracterizan al estado neuquino.

Neuquén se inserta en la economía de mercado a partir de la producción de hidrocarburos y energía eléctrica. El perfil productivo de la provincia se asienta sobre la apropiación de sus recursos naturales como fuente de riqueza y su distribución al interior del territorio local, consolidándose este modelo en los pasados años 90, con la desregulación del mercado hidrocarburífero (García, 2007: 19-22).

Estos procesos se asocian con un estado provincial conformado por un partido político hegemónico: el Movimiento Popular Neuquino ${ }^{5}$, con un histórico y afianzado ejercicio de prácticas clientelares. Es central en esta configuración la política distribucionista del gobierno. Los recursos "se volcarán sobre dos ejes: la obra pública — que canaliza las actividades de la burguesía provincial—y la política social — que atiende la demanda de los sectores empobrecidos-. Esta redistribución se

${ }^{2}$ Se reconoce como Patagonia el área ubicada en el extremo meridional de Argentina, comprendiendo las provincias de Neuquén, Río Negro, Chubut, Santa Cruz y Tierra del Fuego, Antártica e Islas del Atlántico Sur.

${ }^{3}$ Estas agrupaciones se reconocen con el nombre del paraje en el cual se asientan. En el caso de Chiuquilihuín, el nombre de la agrupación es Huala Pereyra y, en el de Aucapán, es Linares. No obstante, estos nombres son muy poco empleados, motivo por el cual utilizaremos las denominaciones que dan cuenta de la identificación que ha primado de la comunidad con el paraje.

${ }^{4}$ Este espacio abarca parte del borde oeste de las provincias de Neuquén, Río Negro y Chubut, comprendiendo un espacio limitado, al norte, por el lago Aluminé y, al sur, por Esquel y la Colonia 16 de Octubre. Se ubican allí grandes Parques Nacionales, el volcán Lanín y un número importante de lagos entre los valles cordilleranos, que se conforman como emblemas del área (Belaustegui, Castañeda, Lazos et. al., 1999: 48-49).

${ }^{5}$ Éste surge en la pasada década del 60 y ha gobernado la provincia en todos los periodos constitucionales desde entonces hasta la actualidad - años 1963-1966, 1973-1976 y 1983 hasta el presente- Cabe recordar que Neuquén es declarada Provincia hacia fines de la última década del 50, siendo Territorio Nacional entre 1884 y 1955. 
efectúa a partir de dos recursos primarios del Estado: las regalías hidrocarburíferas y energéticas y la coparticipación federal" (García, 2007: 23-24).

Así, los territorios no productores de hidrocarburos permanecen supeditados en gran parte a tales aportes. El empleo público y los planes asistenciales efectivizan la dependencia del estado.

En los pasados años 90, al mismo tiempo, se pone en duda la viabilidad futura del modelo sustentado hasta entonces por la provincia. El Estado planificará entonces una política sobre la base de la diversificación económica, ocupando un lugar relevante la promoción de la actividad turística. No obstante, como bien señala García (2007), en realidad estos procesos continúan apelando a la redistribución de los recursos del Estado, más que a la corrección de las desigualdades territoriales.

Por otra parte, al interior de la provincia, nos interesa la situación integral de los pueblos originarios y luego, más específicamente, aquella que se sitúa en relación con la dinámica de su producción artesanal. Esto supone dirigir la atención sobre los aspectos étnicos. Ahora bien, su consideración abarca cuestiones que atienden a diferentes instancias contextuales y hacen a su especificidad más cotidiana. Importan las políticas que implementan los estados nacional y provincial respecto de las poblaciones aborígenes y como éstas han pautado - y pautan — las condiciones en las cuales los pueblos originarios subsisten e intentan garantizar su reproducción social ${ }^{6}$. Interesan asimismo los complejos procesos que atraviesan los movimientos indígenas y las modalidades que adquieren sus luchas y reivindicaciones en el presente. En la provincia de Neuquén, el posicionamiento político y la ingerencia de las organizaciones indígenas afectan fuertemente la vida de las comunidades, implicando planteos reivindicativos y de gestión ${ }^{7}$. Cabe agregar la actuación en las comunidades de Organizaciones no Gubernamentales que intervienen realizando proyectos o acciones puntuales en los ámbitos productivos, de servicios, de infraestructura u organizacionales ${ }^{8}$.

La especificidad étnica de las comunidades abordadas implica asimismo la consideración de su contexto ambiental y condicionamiento histórico, fruto de las sucesivas políticas nacionales y/o provinciales implementadas.

Aucapán y Chiuquilihuín limitan, al norte, con el Parque Nacional Lanín, las veranadas de las estancias "La Papay" y "Los Remolinos" y un campo fiscal; al sur, con la comunidad Atreuco, la estancia "Lolén", la veranada de Biorkman y las

${ }^{6}$ En cuanto a los instrumentos jurídicos, en 1994, en la última reforma de la Constitución Nacional se introduce el reconocimiento explícito de los pueblos originarios y sus derechos — artículo 75, inciso 17_, marcando un hito relevante; el Convenio 169 de la OIT - 1989_, adoptado por Argentina en 1992 mediante la Ley 24071, tuvo un rol importante en la conformación del corpus legislativo nacional. Otro precedente relevante fue la ley 23.302 de "Política Indígena y Apoyo a las Comunidades Aborígenes", sancionada en 1985 y reglamentada en 1989.

${ }^{7}$ Actúa allí la Confederación Indígena Neuquina - CIN-, constituida en 1970 y hoy plenamente activa. Muy recientemente se estaría conformando en algunas comunidades otra organización, con independencia de la CIN y manteniendo incluso algún grado de confrontación con ella.

${ }^{8}$ Intervienen y/o han intervenido en la zona: "Pro-Patagonia", "La Cruzada Patagónica", "Recerca e Cooperazione" y UNMAY —ésta última con la particularidad de ser una ONG conformada exclusivamente por integrantes del pueblo mapuche- . 
estancias "Tres Picos" y "La Atalaya"; al oeste, con el Parque Nacional Lanín y la estancia "Tres Picos"; y, al este, con las estancias "Pilo Lil" y "La Atalaya" (Manazza, 1994). Se observa como las tierras de las agrupaciones se hallan rodeadas por el Estado nacional — a través de la Administración de Parques Nacionales-y por propietarios latifundistas.

A fines del siglo XIX, impulsada por el Estado nacional se produce en la región la campaña militar denominada "Conquista del Desierto", conocida por los mapuches como "El malón de los winka" o "La época de la perdición". Ésta penetra en un espacio profusamente habitado y sumamente dinámico a nivel político y social. Las acciones de guerra culminaron con el desplazamiento de las poblaciones indígenas y con la usurpación por el ejército argentino de los territorios comprendidos en el triángulo de Neuquén. La ocupación territorial de la región occidental y meridional de la provincia - realizada en el marco de la Ley Avellaneda - permitiría la privatización del área y la apropiación de las tierras más ricas y aptas para la ganadería por los empresarios ganaderos, conformándose las primeras estancias como unidades capitalistas de producción (Carpinetti, 2005: 36-39).

Los grupos indígenas fueron desplazados a las zonas más desfavorables e inhóspitas de la región, de difícil acceso y comunicación y con superficies pequeñas y de reducida productividad. Fueron relocalizados en un marco de desprotección legal: como ocupantes de tierras fiscales, lo cual implicó una situación de precariedad absoluta respecto de la tenencia de la tierra y el usufructo de los recursos (Carpinetti, 2005: 39).

Entendemos que es en la articulación de los diferentes contextos y condicionamientos y la experiencia más cotidiana de los pobladores de las agrupaciones, donde debe situarse el análisis de la problemática artesanal de los pueblos originarios.

\section{Las comunidades}

La zona donde se ubican las comunidades de Chiuquilihuín y Aucapan exhibe un relieve montañoso con pequeños valles angostos y profundos, que se hallan a una altura entre 1000 y $1500 \mathrm{~m}$. sobre el nivel del mar. En el sector occidental dominan los bosques, pasando a una zona de estepas hacia el este (Proyecto Pehuenche, 2002: 15).

Chiuquilihuín cubre una superficie de 5.144 ha., en tanto que Aucapán cuenta con 7.487 ha., asentándose la población en cuatro parajes9. Ambas agrupaciones poseen la propiedad comunitaria de la tierra, tienen personería jurídica y organizacionalmente cuentan con una Comisión Directiva, renovable cada dos años. Hay asimismo líderes por sectores o parajes, denominados capitanejos, los cuales se incorporan a la Comisión Directiva (Peralta, 2003b: 3). Ambas comunidades disponen de escuelas en sus parajes y de agentes sanitarios.

Hoy los reclamos de tierras continúan siendo reivindicaciones de numerosas agrupaciones y las actuaciones gubernamentales resultan insatisfactorias. No obstante, cabe señalar que el estado neuquino implementó en la pasada década del 60

\footnotetext{
${ }^{9}$ Éstos son: Aucapán centro, Nahuel Mapi abajo, Nahuel Mapi arriba y Calfuqueo.
} 
una política indigenista de avanzada en relación con el resto del país ${ }^{10}$, reconociendo a comunidades mapuches, asentadas en la provincia, el usufructo de las tierras que ocupaban mediante el establecimiento de reservas — decreto 0737/64 y sus complementarios- (Falaschi, 1994: 6) ${ }^{11}$.

Respecto de los datos poblacionales, los registros indican para Chiuquiliuín un total de 306 pobladores conformando 68 familias (Proyecto Pehuenche, 2002: 17). Hasta la última década del 50-60 se dio una alta tasa de expulsión de la población joven y en edad activa (Peralta, 2003a: 3).

Históricamente las migraciones han sido un fenómeno presente y relevante en las comunidades mapuches de Patagonia. Los grupos domésticos ${ }^{12}$ han sido estructuralmente expulsores de mano de obra, abasteciendo de fuerza de trabajo a distintas ramas y sectores económicos de la región (Radovich y Balazote, 1995: 75). Las dificultades con que cuentan para desarrollar sus actividades productivas - consecuencia de sucesivas políticas estatales de despojo territorial- hacen que éstas suelan ser insuficientes para garantizar su subsistencia, viviendo en condiciones de suma precariedad. Por esta razón, muchos de sus integrantes se han visto obligados a migrar en forma estacional, temporaria o prolongada, incorporándose al mercado de trabajo, ubicándose tanto en medios rurales como urbanos.

En el ámbito rural aún continúa la contratación de trabajadores mapuches en establecimientos latifundistas. Por otra parte, las ciudades del norte de Patagonia han recibido importantes contingentes de tal origen que se insertan en el circuito productivo; estas migraciones a los centros urbanos han revestido gran importancia para la economía regional (Balazote, 1999: 38).

A posteriori de la última década de loa años 60 , se fue produciendo en Chiuquiliuín un paulatino aumento de la población, acelerándose dicho proceso desde 1994 (Peralta, 2003a: 4).

La comunidad de Aucapán registra un número mayor de pobladores que Chiuquilihuín, estando conformada por 750 personas, distribuidas en 130 familias, pero exhibe patrones demográficos semejantes, habiéndose dado también en ella un proceso de crecimiento poblacional (Peralta, 2003b: 4). Esta situación se habría producido en ambas comunidades debido a diferentes factores: la disminución de la demanda laboral en la zona rural, la expulsión de pobladores asentados en otras regiones que se habrían visto obligados a regresar a las agrupaciones, el crecimiento de los servicios comunitarios y la efectivización de planes provinciales de vivienda en las comunidades y la asistencia social por el Estado (Peralta, 2003a: 4, 2003b:

${ }^{10}$ Estos hechos ocurrieron bajo el gobierno de Felipe Sapag, perteneciente al Movimiento Popular Neuquino - MPN - y Chiuquilihuín y Aucapán formaron parte de las 22 comunidades inicialmente reconocidas por la provincia (Falaschi, 1994).

${ }^{11}$ En la actualidad hay en la Provincia de Neuquén 47 Comunidades mapuches reconocidas (Perez Raventós, 2003: 6). Otras fuentes colocan esta cifra en 42, de las cuales 38 tienen su personería jurídica bajo el régimen de la ley provincial $\mathrm{N}^{\circ} 77$, es decir, como asociación civil con un estatuto tipo (http://www.mineria.gov.ar/ambiente/estudios/IRN/neuquen).

${ }^{12}$ Están conformados como unidades de residencia, producción y consumo, que regulan su proceso reproductivo (Balazote y Radovich, 1992: 28). 
5). A esto se agrega el empeoramiento de las condiciones de vida en la ciudad en la última década de los años 90, hecho que llevó al regreso de migrantes urbanos. Este aumento demográfico ha incidido y agravado las dificultades ya existentes respecto de las tierras de las agrupaciones.

\section{1. Actividades económicas}

Luego de la denominada "conquista del desierto", los pobladores de las agrupaciones debieron modificar la modalidad productiva que habían desarrollado hasta entonces, basada en la ganadería extensiva — en amplias superficies de ocupacióny la agricultura en zonas fértiles.

Antes de las campañas militares de fines del siglo XIX, la presencia indígena en el norte de la Patagonia significaba un obstáculo para el desarrollo capitalista de la región. Sin embargo, los procesos productivos, que se implementaron en los territorios mapuches ocupados, requerían, aun en una escala reducida, la incorporación de fuerza de trabajo indígena. Se dio entonces un proceso de reconversión de la mano de obra aborigen, ya que ésta debió adecuarse a los cambios que proponía el modelo económico en relación con el tipo de proceso de trabajo y la utilización de nuevas tecnologías, así como con las profundas modificaciones ocurridas en el campo de las relaciones sociales de producción" (Radovich y Balazote, 1995: 76-77).

En la actualidad, la economía de los grupos domésticos se caracteriza por la multiplicidad y la complementariedad de actividades que deben ser desarrolladas para garantizar su reproducción. Tal diversificación de tareas económicas se conforma como estrategia reproductiva relevante de la comunidad.

Los pobladores practican la ganadería extensiva sobre pastizales naturales, poseyendo vacunos, ovinos y caprinos. Si bien los animales más apreciados son los primeros, la mayor parte de los crianceros poseen animales menores ${ }^{13}$ y suelen tener también algunos caballos. Asimismo, es usual la crianza de aves de corral, especialmente gallinas, destinadas en primer lugar al consumo interno de la unidad doméstica y al intercambio en caso de contar con excedentes.

Los productos obtenidos: pelo y lana se utilizan usualmente para satisfacer necesidades de los grupos domésticas o son vendidos internamente para ejecutar la producción artesanal; en ocasiones se destinan al intercambio con comerciantes; y en otros casos pueden llegar a venderse corderos y/o chivitos y algunos cueros; respecto del ganado bovino, su venta es sumamente ocasional.

Cabe señalar respecto de la ganadería, la mejor situación que presenta Chiuquilihuín sobre Aucapán, exhibiendo una tenencia de ganado promedio por habitante cercana al doble que la segunda agrupación (Gallo e Izquierdo, 2002).

Además de tratarse de tierras marginales, en relación con el crecimiento demográfico de las comunidades, las superficies disponibles para el ganado han ido

${ }^{13}$ En Chiuquilihuín, según datos de la Comisión Directiva recogidos por A. Pinna, en el año 2002, las familias de la comunidad poseían un total de 774 cabezas de ganado ovino, 873 de caprino, 450 de bovinos y 148 de yeguarizos (Peralta, 2003a: 11-13). En Aucapán se registraba un número aproximado a las 3354 cabezas de ganado (Gallo e Izquierdo, 2002: 14). Para el año 2003, se informaba que más del 50\% de los pobladores ya no poseían animales ni para consumo. (Peralta, 2003b: 8). 
reduciendo paulatinamente su tamaño, encontrándose los pobladores con serias dificultades para satisfacer sus demandas. Asimismo, la actividad ganadera está comprometiendo gravemente el recurso forrajero, dado que la carga animal es muy alta para los campos de la comunidad; la permanencia del ganado sobre las pasturas no permite su recuperación, siendo alarmantes los signos de degradación. El efecto del pastoreo también se observa dentro del bosque nativo, que muestra sitios donde es total la ausencia de regeneración natural de especies arbóreas, arbustivas y subarbustivas (Proyecto Pehuenche, 2002: 19-28).

Por otra parte, los pobladores usan el bosque recolectando piñones básicamente para autoconsumo ${ }^{14}$, extrayendo leña - para uso propio y/o intercambio- y obteniendo madera para la construcción de sus viviendas y la elaboración de artesanías. Cabe aclarar respecto de ésta última actividad que, en tanto en Chiuquilihuín tal rubro posee menor importancia que el tejido y, por tanto, no demanda hoy cantidades relevantes de madera, en Aucapán la situación es diferente: allí la producción artesanal en dicho material cobra relevancia y, por consiguiente, su necesidad es muy superior.

En Aucapán, desde fines de los pasados años 80 y durante los 90, se realizaron planes de forestación con especies exóticas ${ }^{15}$. En la actualidad, hay 15 pobladores involucrados en la actividad, que han pasado a ser empleados de planta permanente del estado provincia ${ }^{16}$. En Chiuquilihuín los grupos domésticos sólo se acogieron a los planes de forestación para realizar una parcela comunitaria y algunas prediales, sumando apenas 32 ha. frente a las más de 200 implantadas en Aucapán durante los últimos quince años.

Comparativamente, respecto del entorno natural y el sistema boscoso, los datos indicadores de sustentabilidad muestran en Chiuquilihuín una mejor situación de manejo y conservación que en Aucapán (Fuente: Asentamiento Universitario San Martin de los Andes 2002; citado en Stecher, 2007: 138).

Complementariamente, algunos grupos domésticos practican la horticultura, aunque esta actividad no está generalizada y también encuentra dificultades dada la escasez de tierras y agua; esta faena económica está documentada básicamente para familias de Chiuquilihuín. Los productos obtenidos se destinan sobre todo al consumo familiar y a suplementar al ganado durante el invierno, intercambiándose el excedente. Estas tareas se realizan por mujeres, que se ocupan también del cuidado de los animales de granja.

\footnotetext{
${ }^{14}$ Actualmente en Aucapán esta actividad no es tan relevante como antaño y ha crecido su uso como bien de cambio o venta (Peralta, 2003b: 7).

${ }^{15}$ A cargo de distintos organismos provinciales y nacionales, los objetivos perseguidos fueron “...disminuir los procesos de erosión, lograr un cambio productivo de ganaderos extensivos a forestales y mejorar la situación de carencias básicas en las comunidades mapuche del departamento" (Stecher, 2007: 135).

${ }^{16}$ Como consecuencia de estos planes, se señala que "...muchos de los beneficiarios finalmente mantuvieron los animales logrando una diferenciación respecto al resto de las unidades domésticas y paralelo a ello el ingreso, producto de la relación laboral con el estado" (Stecher, 2007: 35).
} 
Por otra parte, como ya señaláramos, los grupos domésticos se insertan en el mercado no sólo en su condición de productores - y consumidores de mercancías-, sino también en su situación de abastecedores de la fuerza de trabajo requerida por los distintos circuitos económicos.

Los pobladores de las comunidades complementan las actividades prediales con tareas extraprediales. Se desempeñan como asalariados dentro de las comunidades: en las escuelas, los puestos sanitarios, diferentes instalaciones de infraestructura, la provisión de servicios etc., o externamente en el medio rural —en las estancias de la zona - o urbano - trabajos en la construcción, changas, etc.—, con carácter permanente o temporal. En el primer caso, en la provisión de servicios a la comunidad, se observa la actuación clave que desempeña la provincia como ente empleador.

Situadas las agrupaciones en un área natural atractiva, se estima que poseen potencialidades para un desarrollo turístico. La ruta internacional a Chile y la vecindad con el Parque Nacional Lanín son consideradas factores que favorecen esa posibilidad. Pese a que en la actualidad la realización de actividades turísticas no se halla extendida en las comunidades, se registra interés y un involucramiento reciente de algunos pobladores en emprendimientos de este tipo. Por ejemplo: en Aucapán, unos pocos pobladores se organizaron para recibir visitantes y guiar cabalgatas, ofreciendo una estadía de algunos días, visitando distintos puntos del territorio y brindando alojamiento, comidas y servicios generales (Peralta, 2003b: 11). Tales experiencias turísticas se conforman como otra fuente de ingresos, en el marco de la diversificación económica que experimentan las agrupaciones.

Cabe considerar de todos modos que hoy día, aunque el turismo posee relevancia en la región - corredor de los lagos_- su incidencia en las comunidades se relaciona básicamente con su potencialidad como consumidor de la producción artesanal.

Por otra parte, los pobladores son beneficiarios de planes de empleo a nivel nacional — "Plan Jefes y Jefas de hogar"- y provincial — "Planes Trabajar"/ley provincial 2128 - implicando ambos subsidios una contraprestación por los favorecidos; reciben asimismo pensiones y jubilaciones.

En ambas comunidades los ingresos percibidos por los planes constituyen un aporte relevante a las economías domésticas. Se puede afirmar que la casi totalidad de los hogares perciben al menos uno de estos estipendios - contando algunos hogares con los dos- derivados de políticas públicas para paliar la pobreza y desocupación (Peralta 2003a: 17, 2003b: 12).

Las difíciles condiciones productivas - tierras marginales, limitaciones de espacio, degradación de suelos, pobre disponibilidad de pasturas y agua, pérdida de animales por factores climáticos asociados a problemas nutricionales y mortandad perinatal, etc. - no admiten la resolución predial de las economías familiares. Siendo que la mayor parte de los grupos domésticos de las comunidades no puede basar su subsistencia exclusivamente en la actividad ganadera y dadas las dificultades que hallan los pobladores para obtener trabajo asalariado, es comprensible la relevancia que adquiere en las agrupaciones la percepción de ingresos a través de los planes mencionados. La presencia del estado, como señaláramos anteriormente, 
es contundente en las comunidades de la provincia y posee una sólida impronta asistencialista. Las familias reciben asimismo una o dos cajas de alimentos de origen estatal, garrafas de gas a precios reducidos y leña.

Comparativamente en términos socioeconómicos —además de las condiciones medioambientales diferenciales-, Chiuquilihuín se encuentra en una situación menos crítica que Aucapán ${ }^{17}$.

\section{Las actividades artesanales}

En la dinámica que planteamos, donde se conjugan distintos niveles contextuales y especificidades y prácticas de los sujetos sociales, centramos el análisis de la problemática artesanal de los pueblos originarios. Interesan los procesos que se desarrollan, identificando en ellos las intervenciones del mercado, del estado y de las poblaciones indígenas en tanto pivotes que coparticipan en su articulación.

Nuestra modalidad de análisis se inscribe en una perspectiva general, desde la cual subrayamos enfáticamente la necesidad de situar la producción artesanal dentro de un marco global, es decir, atendiendo a su inserción en un mercado de índole capitalista. Respecto del concepto artesanías, la expresión encubre un complejo contradictorio de objetos y procesos, que no puede ser abordado como si se tratara de un fenómeno coherente, homogéneo y unificado. Diversos autores han señalado tal diversidad, así como la dificultad de definir las artesanías por una esencia a priori o por una sumatoria acumulativa de rasgos que les serían propios (García Canclini, 1982; Novelo, 1976; Novelo, 1993). Adoptamos la perspectiva de V. Novelo, quien plantea un enfoque de la cuestión atendiendo a la consideración de las artesanías como proceso y no como resultado (1976: 7, 1981: 197). El foco de atención se desplaza entonces del producto cultural, a su producción social, es decir, a los procesos de elaboración en los cuales las prácticas sociales, las relaciones y las instituciones pueden ser detectadas (García Canclini, 1982). Importa además recuperar en el análisis las particularidades de las producciones artesanales, que se conforman como valores de uso y de cambio y poseen tanto una dimensión simbólica como económica (García Canclini, 1982; Novelo, 1976; Novelo, 1993). Ello implica considerar las prácticas simbólicas en relación con sus condiciones materiales de producción (García Canclini, 1982).

Las producciones culturales de los pueblos originarios han sido usualmente consideradas un ámbito dilecto de expresión identitaria. En este campo han ingresado las piezas artesanales, constituyéndose en locus privilegiado de tal atribución; dicha consideración reconoce profundidad histórica, siendo compartida por los diferentes agentes sociales que guardan relación con tales productos. Ahora bien, en el conjunto

${ }^{17}$ Respecto a la actividad ganadera, la primera se halla en situación más favorable debido a su cercanía a zonas húmedas de la cordillera, con tierras mas aptas para el ganado. Además es mayor la tenencia de tierras promedio por familia, dada la menor densidad poblacional. En cuanto a la posibilidad de contar con ingresos extraprediales, las alternativas de los pobladores de Chiuquilihuín son mayores que las que poseen los de Aucapán. Por ejemplo, la incidencia de los planes sociales sobre el total de población es mayor en la primera $-24,2 \%$ de beneficiarios - que en la última $-14,3 \%$ de beneficiarios- (Gallo e Izquierdo, 2002). 
de las manifestaciones culturales asociadas a las poblaciones aborígenes - lengua, educación, cosmovisión, etc.- - la producción artesanal se constituye como marca identitaria, pero, al mismo tiempo y a diferencia de los otros tópicos, permanece fuertemente ligada y afectando a la reproducción más cotidiana de los grupos domésticos. De este modo, en las comunidades analizadas operan procesos, que permiten apreciar situaciones diferenciales respecto del lugar conferido a la producción artesanal como elemento conformador de la identidad étnica del pueblo mapuche.

Adoptamos aquí la definición de identidad étnica ${ }^{18}$, propuesta por M. Bartolomé (2006: 83), quien la entiende como: “...una construcción ideológica histórica, contingente, relacional, no esencial y eventualmente variable, que manifiesta un carácter procesual y dinámico, y que requiere de referentes culturales para constituirse como tal y enfatizar su singularidad, así como demarcar los límites que la separan de otras identidades posibles".

Hemos señalado en párrafos anteriores, tanto aspectos que son comunes a Chiuquilihuín y Aucapán, como particularidades que las diferencian. Un punto a marcar es que las mejores condiciones generales - medioambientales y socio-económicas - , presentes en la primera comunidad, disminuyen la relevancia de la tarea artesanal como fuente de ingresos para los grupos domésticos. En la segunda agrupación, por contra, la producción de artesanías constituye prácticamente el principal recurso para sus pobladores ${ }^{19}$.

La importancia entonces que adquiere la actividad a nivel económico resulta variable, acorde tanto a condicionamientos de distinta índole como a especificidades de las unidades domésticas de las comunidades. La elaboración de artesanías se inserta en el marco de la multiplicidad de labores prediales y extraprediales que realizan los pobladores mapuches para garantizar su subsistencia, quienes privilegian una u otra de acuerdo a su mayor rentabilidad y/o a los recursos disponibles para ejecutarla, siendo que la diversificación de actividades se conforma, como ya hemos señalado, a modo de estrategia reproductiva central de las agrupaciones.

En la actualidad, se observa un incremento de la producción artesanal vinculada con el ya mencionado auge del turismo en la región. Anteriormente, la relevancia de la tarea era menor; en un contexto diferente, otras faenas resultaban más rentables, ocupando mayormente a los pobladores.

En la vida cotidiana, en tanto, la actividad artesanal adquiere una modalidad específica. Es factible desarrollarla en tiempos/momentos del día que quedan liberados de otras tareas. Y en tal sentido, resulta relevante además para los pobladores que la

${ }^{18}$ Tratándose de un campo multidimensional e interdisciplinar, las aproximaciones teóricas a las identidades étnicas reconocen diferentes perspectivas, existiendo una amplia bibliografía al respecto. No obstante, no es el objetivo de este trabajo especificar las distintas propuestas y efectuar su revisión crítica.

${ }^{19}$ Los registros indican 100 familias produciendo artesanías en madera para la venta (Peralta, 2003b: 10). Además, del total de ingresos por hogar — considerando actividades ganaderas, artesanales, empleos asalariados y subsidios y pensiones-, el expendio de artesanías se ubica en el primer lugar — con un 40\%-, en tanto que en Chiquilihuin se sitúa en tercer término —con un 20\%- (Espósito, 2005: 49). 
ocupación, al realizarse en el ámbito doméstico, permite continuar atendiendo distintas labores, mientras se generan recursos económicos para la unidad doméstica.

Asimismo, la actividad puede llevarse a cabo estacionalmente respondiendo a diferentes situaciones:

- Aumento en la demanda de los productos artesanales, que vuelve más rentable su elaboración que la ejecución de otras labores — por ejemplo, durante el verano, cuando aumenta el caudal turístico-.

- Menor requerimiento de las otras ocupaciones prediales o directamente su suspensión, lo cual posibilita dedicar ese tiempo a la producción de artesanías — por ejemplo, por razones climáticas estacionales-.

- Interrupción o carencia de trabajo extrapredial, actuando directamente la actividad artesanal como reemplazo del mismo.

Los productos elaborados por las comunidades, en Chiuquilihuín, consisten centralmente en tejidos y se trata de una actividad realizada por las mujeres. Hay escasos artículos en madera, que se ejecutan por unos pocos hombres de la comunidad; los registros dan cuenta solamente de seis artesanos en este rubro con una producción sostenida.

En Aucapán, por el contrario, son mayoritarias las artesanías en madera y también se trata de una labor masculina. El tejido se encuentra menos extendido ${ }^{20}$ $\mathrm{y}$, desde hace algunos años, un grupo reducido de pobladoras han comenzado a realizar platería.

\section{1. Los tejidos de Chiuquilihuín}

Respecto a los tejidos, éstos se elaboran en telar. El tipo más común entre los mapuches es el telar vertical con urdimbre vertical; hay también uno con urdimbre horizontal, que se usa básicamente para elaborar fajas.

El pueblo mapuche reconoce una larga tradición en esta actividad. Más allá de los registros arqueológicos, son numerosos los testimonios de cronistas y viajeros acerca del arte del hilado y tejido mapuches. Los textiles fueron no sólo piezas de uso en la vida cotidiana y ceremonial, sino que se constituyeron en importantes artículos de intercambio, conformándose incluso como moneda de cambio.

Ha sido una tarea realizada antiguamente por las mujeres, quienes llevaban a cabo la totalidad del proceso productivo. En la actualidad, si bien hay un predominio femenino, como ya señalamos, el tejido ha dejado de ser una actividad exclusivamente de mujeres.

En el pasado los objetos elaborados se relacionaban básicamente con la vestimenta - paños tejidos para cubrir el cuerpo, que usaban hombres, mujeres y niños; capas; fajas para la cintura y la cabeza; ponchos y mantas (Conejeros, 2004) - y con el apero de montar — confeccionándose diferentes piezas, entre ellas: peleras/ os, piezas de tejido que se colocan sobre el lomo del caballo; maletas, elementos

${ }^{20}$ Labor tradicionalmente femenina, en la actualidad también se ejecuta por los hombres. En Aucapán incluso, un grupo de pobladores varones es quien elabora tejidos de mayor valor - con diseños más complejos, dimensiones más amplias, etc.- y cuenta con buenos contactos para su comercialización. 
que se ubican en el recado y se usan para el guardado de elementos, denominados usualmente alforjas; cinchas, etc.-.

En la actualidad y para la venta, se continúa con la producción de fajas, ponchos, mantas - matras y matrones - y también enseres para el ganado equino; a estos artículos se suman colchas, chalecos, tapices, alfombras, caminos, bolsos y cinturones.

En Chiuquilihuín la actividad cobra relevancia a partir del interés de un grupo de mujeres en el aprendizaje del tejido, materializándose en un taller que se arma a partir de la implementación de subsidios laborales. Como ya mencionamos, los ingresos percibidos mediante los Planes implican una contraprestación por los beneficiarios; que, en este caso, consistió en capacitación en textiles tradicionales — con una exigencia horaria de cuatro horas diarias-.

Al frente del Taller, denominado Amulein Nimin — Vamos juntas a la labor-, se ubicó una "capacitadora", pobladora con profundo conocimiento de la labor y respetada por sus pares; el número de miembros se ha mantenido entre doce y catorce personas, con pequeñas fluctuaciones. Allí se han instruido en las distintas tareas vinculadas con los textiles: preparación de la lana, hilado, conocimiento de técnicas de teñido y tejido en telar vertical.

Para las mujeres, inicialmente, se habría tratado básicamente de "aprender", de iniciar un camino de conocimiento sin tener en el horizonte cercano el tema de la venta.

En ese principio nosotras entramos a capacitarnos así nomás porque nos interesaba ir rescatando... y después bueno, ya se volvió a formar un grupo... y bueno ahí fueron integrándose y también ya venían con la idea de seguir capacitándose para aprender también. Pero hubieron antes de las que formamos el grupo - inicial— que nos interesamos nada más que en solo aprender (Tejedora integrante de la agrupación).

Está presente fuertemente en el discurso de las pobladoras la intención de valorar las tradiciones ${ }^{21}$, de rescatar un saber y una práctica que se está perdiendo y se estima de valor cultural identitario.

Antes de que funcionara el taller, antes de que se hiciera esto, bueno... esto era una cosa que se estaba perdiendo muchísimo en la cultura, que se estaba perdiendo muchísimo entre nosotras y una de las propuestas que hicimos nosotras fue de volver a rescatar y seguir realizando este trabajo que hacían los antepasados (Tejedora integrante de la agrupación).

${ }^{21}$ Hervieu-Leger señala que aquello que define esencialmente a la noción de tradición, “...es el hecho de conferir al pasado una autoridad trascendente para regular el presente", siendo que las bases de tal autoridad no se hallan en la antigüedad — como pareciera a simple vista — sino en "la convicción de que la continuidad con el pasado es capaz de incorporar incluso las innovaciones y reinterpretaciones que exige el presente" (citado en Giménez, 2000: 19). 
Se menciona que en la comunidad quedaban muy pocas tejedoras. Y, si bien el "saber" no se halla generalizado en la Comunidad, la actividad se considera por los pobladores parte integrante de su cultura ancestral; en tal sentido, se trata de un conocimiento, una práctica y un producto valorados, estimados en su carácter tradicional y reconocidos como elementos representativos de su identidad. Tales artículos aún poseen para los miembros de la comunidad importantes aspectos simbólicos - los cuales permanecen en tensión y complejamente imbricados con aquellos de índole económica-.

Por otra parte, la adquisición de conocimientos relacionados con las diversas actividades artesanales reconoce distintos canales de instrucción. Éstos comprenden el ámbito familiar, pero se sitúan también muy frecuentemente fuera de las comunidades, comprendiendo agentes externos a ellas, pero con los que han interactuado históricamente - instituciones estatales y diversos agentes no gubernamentales-.

En el caso del tejido - a diferencia de otros rubros-, es relevante la filiación y asume importancia la línea femenina: se mencionan madres, tías y abuelas que tenían algún conocimiento y/o practicaban la actividad; este registro adquiere espesor cultural y está presente en la noción de un saber que, transmitido o no dentro de la unidad doméstica, hilvana en continuidad las distintas generaciones de mujeres.

Respecto a la dinámica del trabajo en el Taller, usualmente la preparación de la lana y del teñido se hace en las casas, el tejido en el taller y el hilado indistintamente. Se privilegia el uso de lanas y tintes naturales, el manejo de técnicas tradicionales y la elaboración de piezas con diseños ancestrales; cada tejedora, por su parte, elige libremente las piezas que desea elaborar.

La lana se obtiene de los animales propios, ya que la mayoría de las artesanas posee ovejas; quien no tiene ganado consigue el material mediante compra a pobladores de la agrupación o de otra comunidad; también se adquiere de esta forma, en ocasiones, para lograr ciertas tonalidades, porque en Chiuquilihuín casi no hay animales de colores. Los tintes para el teñido se obtienen de plantas de la zona, yuyos, raíces, corteza de árboles e incluso de la yerba mate que se consume.

En cuanto a los diseños, las mujeres copian los enseñados por la maestra capacitadora. Muestran suma insistencia en la repetición de motivos y figuras y en la aseveración de que éstos tienen "significados", hecho que refuerza el afán por su preservación. Pese a que no exhiben un gran conocimiento sobre ese tema, dicho tópico posee suma relevancia para ellas.

Las mujeres mencionan y muestran tejidos con diseños de animales: choique, araña, pájaros. Sostienen que muchos fenómenos y elementos del mundo natural tendrían sus símbolos en los tejidos, aunque todavía no los han podido reproducir en su labor:

Lo hemos intentado si,...nos interesa mucho... pero como en esto es muy difícil..., cuesta... pero igual, con el tiempo yo creo que va a salir... porque eso también tiene su símbolo y sus significados, porque esto lleva su nombre mapuche también [señala una figura trazada en una pieza tejida]; es muy difícil de nombrarlo, yo por ejemplo... no sé muy bien; hay algunos que identifican [con] el sembrado de la 
tierra, otros [con] el símbolo de algún pájaro que es también de acá de la zona... (Tejedora integrante de la agrupación).

Los tejidos exhiben una variada iconografía, que representa elementos centrales de su cosmogonía. Al mundo textil se han asociado ritos iniciáticos vinculados con distintos momentos del ciclo vital de la mujer, así como mitos y relatos ancestrales. Los textiles son valorizados por las productoras que reconocen a esta producción como parte de las tradiciones ancestrales del pueblo mapuche. Los pobladores poseen registro de su vigencia y relevancia en el pasado, condensando múltiples aspectos de la cosmovisión y de las prácticas de los antepasados. Éstos últimos, como bien señala Giménez, adquieren importancia no por si mismos sino en tanto "transmisores autorizados de una compleja herencia cultural" (2000: 19). El desconocimiento actual del significado y contenido de muchos de los tópicos correspondientes al tejido, así como el hecho de que no todos los integrantes de la comunidad posean los saberes asociados a la actividad, no cancelan la certeza de los integrantes del pueblo mapuche acerca de la compleja existencia, profundidad histórica y densidad de la trama del trabajo/ arte textil.

Entendemos que la apropiación e interiorización del conjunto de repertorios culturales emblemáticos de la comunidad por los actores sociales conforman una dimensión fundamental de los procesos de construcción identitaria, mediante los cuales aquéllos delimitan simbólicamente sus fronteras. Retomamos en este punto un aspecto de la definición de identidad étnica propuesta por G. Jiménez (2000: 12), quien se interesa por situar la relación entre identidad y cultura ${ }^{22}$ : “...la identidad es el conjunto de repertorios culturales interiorizados (representaciones, valores, símbolos...), a través de los cuales los actores sociales (individuales o colectivos) demarcan sus fronteras y se distinguen de los demás actores en una situación determinada, todo ello dentro de un espacio históricamente específico y socialmente estructurado".

Los tejidos, objetos artesanales, constitutivos de la identidad étnica de los pobladores mapuches, fungen como diacríticos. Se reconocen en ellos, asociando sus características a valores simbólicos: saberes, modos de vida, formas de conocimiento ubicados en el pasado, en un tiempo remoto que interesa "recuperar", pero no para revivirlo sino para posicionarse mejor en el tiempo presente.

Por otra parte, el Taller no es sólo un espacio de aprendizaje y producción, sino que se conforma también como ámbito de comercialización ${ }^{23}$. El precio de venta lo fija cada artesana. No obstante, hay acuerdos básicos sobre los valores de los productos ofrecidos. La tarifa depende del diseño, de los colores, del tamaño y tiempo

\footnotetext{
${ }^{22}$ Sobre la vinculación identidad-cultura, estimamos relevante el trabajo de Guillermo Bonfil Batalla (1992).

${ }^{23}$ Tejedoras de la comunidad, ajenas al recinto, también expenden allí sus tejidos, que pueden estar elaborados con materiales no naturales. Cabe mencionar que las mujeres que conforman el Taller tejen también con dos y cuatro agujas y usan la técnica de crochet, elaborando medias, gorros y otros productos de carácter menos "tradicional"; trabajan asimismo por encargo; en estos casos suelen usar lana industrial y tintes no naturales. También se vende en el Taller algunos artículos en madera, elaborados por pobladores de la comunidad.
} 
de ejecución de la pieza; usualmente los artículos más requeridos son aquellos de tamaño pequeño.

\section{2. Las piezas en madera de Aucapán}

Acerca de la tarea en madera, hay antecedentes de que el pueblo mapuche elaboraba piezas en este material, tanto utensilios domésticos - fuentones, morteros, bancos, etc. - como objetos rituales; en este último caso se mencionan las máscaras o kollon, utilizadas en el Nguillatún, los chemamull - troncos tallados con fines funerarios-y los rewe; también se realizaban instrumentos musicales como kultrunes y pifilkas (Espósito, 2005: 50; Espósito, 2004: 185).

En Aucapán, en la actualidad y continuando con una tendencia histórica, claramente se observa la predominancia de la elaboración de piezas para el mercado, habiéndose dado una pérdida progresiva del valor de uso que poseían los artículos para la comunidad. El trabajo en madera con fines comerciales se habría desarrollado en la agrupación hace aproximadamente tres décadas.

Hoy día y para la venta, se continúa con la producción de fuentes, bancos e instrumentos musicales; la factura de éstos últimos se torna menos elaborada y disminuye en complejidad al ser destinados a la comercialización. Y se agregan copetineros de diferentes formas y tamaños, platos, bandejas, cuencos, tazas pequeñas, figuras decorativas de animales, etc.

Sobre las características de los objetos elaborados cabe señalar que la mayoría de las piezas y diseños de diferentes productores guardan semejanzas, pero no sólo entre los pobladores mapuches, sino incluso respecto de artesanos urbanos de distinta procedencia étnica ${ }^{24}$.

En la agrupación, algunos registros mencionan un número aproximado de 160 productores y más de un poblador por familia realizando esta actividad (Espósito, 2005: 65). Si bien se trata de una tarea masculina, en la actualidad las mujeres se están incorporando a la producción. El número de artesanos en madera se incrementó en los últimos años a partir de la crisis económica que afectó al país en el 2001. Asimismo las precarias condiciones en que se halla la comunidad respecto de sus recursos económicos - ya señaladas anteriormente y comparativamente inferiores a Chiquilihuín - contribuyen a la relevancia que adquiere la actividad en el conjunto de las economías domésticas. Los pobladores marcan en su discurso constantemente la preeminencia que posee tal producción: "Nosotros dependemos de las artesanías... es nuestro trabajo" (artesano en madera, integrante de la agrupación); "... toda la comunidad es artesana, otro trabajo no hay..." (artesano en madera, integrante de la agrupación); [La venta de artesanías] "es la única entrada de plata que tenemos..." (artesano en madera, integrante de la agrupación).

Y muestran asimismo invariablemente su estimación en tanto "salida económica". La producción de artesanías en madera se plantearía para los productores, menos con la impronta de una pauta "tradicional", que habría que mantener y repetir

${ }^{24}$ Este punto está estrechamente vinculado a la consideración de la instancia de venta como espacio donde también se dirime la legitimidad de la producción artesanal indígena. 
por constituir un elemento "identitario" étnico del pueblo mapuche, que como una actividad económica — con posiblidades creativas y/o componentes estéticos, según unos pocos artesanos-, que posibilita la obtención de ingresos para la manutención del grupo doméstico.

Respecto de la pericia sobre el trabajo en madera, ésta se considera por los pobladores más como un conjunto de competencias y técnicas, aprendidos por cualquiera de los miembros de la unidad doméstica en algún momento de su ciclo vital - guiado por motivos económicos y laborales y adquirido a través de diferentes vías-, que como producto cultural de origen ancestral.

Los canales de instrucción son variados y abarcan distintos ámbitos: familiar, institucional, informal, personal. El aprendizaje de la actividad trasciende ampliamente el ámbito del grupo doméstico; éste no se constituye necesariamente como canal prioritario de acceso a la misma. Pero además, aun cuando la instrucción se imparta en él, cabe marcar que de ninguna manera alude a un conocimiento apreciado como "bien familiar/ hereditario", recuperado en su profundidad temporal y atávica (Rotman, 2007b).

La competencia de la tarea en madera no es usualmente asociada por los miembros de la comunidad con los "saberes" que conformaron el capital de conocimiento atribuido a los antepasados, comunicado generacionalmente, distinguido y recuperado como marca identitaria étnica y exhibido y reconocido en tanto tal; en saberes y objetos la dimensión simbólica se subordina a la mercantil.

Puede presumirse que los productos en madera son valorizados por los productores en la medida en que su factura hace a su reproducción, al mantenimiento de las condiciones de su vida cotidiana y en tanto "recurso" al cual se puede apelar, toda vez que las condiciones estructurales y coyunturales lo tornen necesario y factible y mientras desde el Estado y el mercado - cada uno por sus razones específicas - se estime a esos objetos como "representativos" de estas poblaciones indígenas, plausibles de promocionarse y comercializarse y atractivos para comprarse.

En cuanto a la dinámica de la producción, la materia prima utilizada es fundamentalmente lenga — nothofagus pumilio - y bajos porcentajes de araucaria - araucaria araucana - Su búsqueda es una tarea individual y en ocasiones familiar. Los bosques habitualmente se hallan distantes de las viviendas, allí se recurre al volteo del árbol seleccionado - usándose hacha y/o motosierra-, o bien se recoge la madera caída sobre el terreno; el acarreo se realiza en forma manual o con animales — caballos o bueyes - ${ }^{25}$. A posteriori, se preparara el material. Este proceso implica el estacionamiento de la madera y puede durar entre uno y tres meses. Se la entierra hasta el momento de trabajarla, o bien se la estiba bajo techo; antiguamente se hervía el material seco en grandes recipientes de 200 litros (Espósito, 2005: 60). Luego se elabora la pieza utilizando escasas herramientas: hachas pequeñas, mai-

${ }^{25}$ Como ya adelantáramos, las actuales condiciones de existencia y las necesidades de reproducción de los grupos domésticos implican una presión creciente sobre el recurso de la madera y una degradación cada vez mayor del bosque nativo, dificultando un manejo sustentable de los recursos. 
chiwes - herramienta elaborada por el artesano, consistente en la hoja de una pala o elástico de auto, atada a un mango de madera-, raspadores, limas y lijas.

El estado neuquino interviene en el tema artesanal de manera directa a través de la empresa estatal Artesanías Neuquinas - $\mathrm{AN}$ - Sus funciones consisten en la promoción de la actividad, actuando como órgano comercializador de la producción de las comunidades indígenas de la provincia. Interesa señalar, no obstante, que la institución posee incidencia en la etapa de producción.

AN plantea a los artesanos diversos requerimientos que abarcan el uso de determinadas herramientas estimadas "antiguas/tradicionales" — ciertas hachas y hachuelas - sobre otras más "modernas" 26 y el señalamiento del tipo de objetos y características estéticas que deben reunir las piezas — contemplando incluso la introducción de nuevos productos-. AN adopta una posición en la cual opera, por una parte, como organismo decisorio y garante de aquello que conforma la "tradición" de los pueblos originarios y, por otra, procede constituyéndose en institución que fija e impulsa las modificaciones y cambios en la producción. Se conforma, de esta manera, una modalidad de acción específica que no sólo expresa la desigualdad que permea las relaciones entre las comunidades y las instituciones estatales, sino que revela como tales entes oficiales se constituyen en órganos de legitimación de la producción artesanal de las agrupaciones (Rotman, 2007b) ${ }^{27}$.

Los agentes externos a las comunidades que intervienen en el ámbito productivo no se limitan exclusivamente a $\mathrm{AN}$, sino que incluyen a operadores particulares e instituciones privadas que interactúan con las agrupaciones. En Aucapán es relevante la estancia Cerro Los Pinos. Allí se solicita a los artesanos en madera la elaboración de determinados artículos, fijándose motivos y tamaños. En la actualidad el requerimiento se vuelca a piezas decorativas, con figuras de animales - lechuza, ñandú, pájaros, etc. - y volumen pequeño. Los productos se destinan a turistas que valoran sus atributos y la facilidad de su traslado.

Artesanías Neuquinas y los dueños de la estancia Cerrro Los Pinos operan como reformuladores y decidores de las características de la producción artesanal.

\section{Las instancias de la comercialización}

Como ya mencionáramos, en la actualidad hay una fuerte promoción del turismo en la región y los registros dan cuenta del fuerte crecimiento de la actividad en el corredor de los Lagos Patagónicos.

Algunos Departamentos de la provincia son más receptivos que el de Huiliches ${ }^{28}$; en tal sentido las comunidades que viven en esas zonas se hallan en mejores condiciones de acceso al turismo. En el caso que tratamos, las agrupaciones no poseen

${ }^{26}$ Sobre la incidencia de las herramientas empleadas en el formato de los objetos, los tiempos de producción y el recurso maderero, consultar Rotman (2007a).

${ }^{27}$ Cabe insistir en que los fenómenos de construcción y legitimación identitaria tienen lugar en un escenario conflictivo de interacciones interétnicas y se insertan en el marco de relaciones de hegemonía y subalternidad.

${ }^{28}$ Es el caso, por ejemplo, del Departamento Lácar, donde se ubica la ciudad de San Martín de los Andes, y del Departamento Los Lagos, donde se encuentra Villa La Angostura; ambos con agrupa- 
tales facilidades y deben "atraer" a los visitantes para que "ingresen" en ellas y adquieran sus productos.

Chiuquilihuín se encuentra cercana a la ruta que conecta Junín de los Andes con el vecino país de Chile y esto facilita el ingreso de turistas. Allí el Taller, atendido por las artesanas, se constituye en el principal canal de venta para los tejidos de la comunidad, sosteniendo un buen funcionamiento. Un cartel promocional sobre la ruta, alerta a quienes circulan, sobre el local de expendio, publicitado también por radio y en folletos que se ubican en la Secretaría de Turismo de la ciudad. La posibilidad de no tener que trasladarse a la ciudad y el hecho de que los precios son fijados por las trabajadoras, conforman ventajas relevantes de esta vía de comercialización. Cabe señalar, en este sentido, que Aucapán no posee local de venta en la comunidad.

Las distintas ferias que funcionan en la ciudad de Junín de los Andes conforman otros canales de expendio que utilizan ambas comunidades: "La Rural" —en enero-, la "Fiesta del Puestero" — en febrero-, la "Semana de la Artesanía Aborigen" - en julio - ${ }^{29}$. En ocasiones, los pobladores ubican sus piezas en el "Paseo de los Artesanos", situado también en la ciudad cabecera y espacio donde venden su producción los integrantes de la "Asociación de Artesanos de Junín de los Andes" -que agrupa a los trabajadores por su actividad y no por su pertenencia étnica-, dejándose los artículos en consignación.

También se expenden los productos a locales comerciales, principalmente de Junín y San Martín de los Andes. En tales casos, pocas veces el pago se realiza en efectivo, usualmente los artículos se dejan en consignación. Algunos artesanos venden también a comercios de otras ciudades de la provincia.

Otra vía de comercialización es la ya mencionada estancia Cerro Los Pinos ${ }^{30}$; los artesanos la evalúan como una buena opción, ya que los precios obtenidos son estimados como superiores a los abonados por los locales comerciales y por Artesanías Neuquinas.

Un canal de venta que guarda suma relevancia para Aucapán es Artesanías Neuquinas. Chiuquilihuín, por su parte, no vende a esta empresa. Las mejores condiciones de vida que posee la comunidad, contar con un local de venta directa al turismo y elaborar principalmente tejido - rubro para el cual otros canales de expendio ofrecen precios mayores - son factores que motivan esta decisión.

ciones mapuches asentadas en dichas áreas. En el primer caso las comunidades se sitúan directamente en lugares de interés turístico y sobre sus rutas de acceso (Rotman, 2007a).

${ }^{29}$ En estos eventos se venden distintos productos y comidas "regionales". Suelen ofrecerse además espectáculos artísticos y desarrollarse distintas actividades recreativas. En algunos, los artesanos deben abonar un canon por su participación, en otros, se asiste por invitación. En ciertos casos, Artesanías Neuquinas se hace cargo de la concurrencia de los pobladores. Esto último sucede respecto de Aucapán, ya que Chiquilihuin se maneja con independencia de dicha institución.

${ }^{30}$ Este sitio funcionaba usualmente como lugar donde los pobladores se abastecían de los productos más cotidianos y además vendían sus productos artesanales. Algunos recuerdan incluso que, si se contraían deudas, éstas podían ser saldadas al año siguiente con dinero o producción artesanal. 
AN opera en la agrupación Aucapán durante todo el año ${ }^{31}$. Muchos artesanos, si bien estiman desventajosa la relación con la empresa debido a los precios abonados, se vinculan con ella para garantizar la colocación de su producción a lo largo del ciclo anual. AN exhibe "continuidad" en su operatoria y mantiene además una cierta "regularidad" en los volúmenes de compra, características ambas sumamente valoradas por los productores.

Respecto de "la forma de pago" que emplea AN con los productores, ésta es en efectivo y se abona el importe total en el momento de la transacción. El flujo inmediato de dinero, que implica esta modalidad, es una condición sumamente valorada por grupos domésticos con economías pauperizadas. Comparativamente resulta una ventaja sobre muchos de los locales comerciales, en los cuales los productos se dejan "en consignación" y se desconoce cuando se cobrará.

No obstante, un tema central es el "precio" que AN abona por las piezas. Tal importe es estipulado por la empresa e impuesto a los productores. Para los artesanos se trata de montos bajos, no consecuentes con el valor de los productos, los cuales no les dejan prácticamente margen de ganancia. Pese a la relevancia de tal hecho, los pobladores mantienen este canal de venta debido a las características ya señaladas de continuidad, regularidad y pago en efectivo.

Por otra parte, para realizar las transacciones, AN se traslada a las Comunidades. Tal característica de "desplazamiento" hacia las agrupaciones resulta una ventaja para los artesanos, ya que no se ven obligados a transportar su producción. Hay que considerar que todo desplazamiento supone una erogación monetaria que resulta limitante para los productores. Las distancias a ser recorridas pueden ser extensas y las condiciones de las rutas y caminos poco favorables. Además el traslado implica que son los artesanos quienes asumen los posibles riesgos respecto de la integridad de las piezas.

Cabe considerar aquí que la instancia de venta se conforma como un espacio donde también se dirime la legitimidad de la producción artesanal de los pueblos originarios.

Ámbitos como el Taller de Chiuquilihuín y los locales de Artesanías Neuquinas operan como dadores y garantizadores de la identidad mapuche - configurando dos casos significativos-.

El primer caso es producto de una atribución y una valoración que emana de la propia comunidad. Y tiene su correlato en una cierta modalidad de recepción por el público. La adquisición de los bienes en forma directa a quienes los elaboran configura un atractivo, un "plus" que presenta el producto. Incluso la posibilidad de que los artesanos ejecuten su tarea a "la vista" de los compradores resulta un factor propicio para la comercialización. La venta en el expendio, sin intermediación, en el entorno de la propia comunidad, y con la presencia del productor constituyen un "valor agregado" de la producción.

${ }^{31} \mathrm{El}$ accionar de la empresa se inscribe en la política clientelística y asistencialista que caracteriza al estado neuquino. 
El segundo caso es producto de la autoridad con que resulta investida la empresa en tanto organismo estatal, con carácter de experto y con poder decisorio entonces respecto a los atributos que identifican a las producciones mapuches.

Como bien señala Giménez (2000: 14), el Estado en las sociedades modernas se reserva "la administración de la identidad" mediante dispositivos específicos de control. De esta manera, siendo la identidad un objeto de disputa, son quienes detentan el poder, los que se arrogan la autoridad legítima para reconocer e imponer una visión y definición sobre los "otros" (Bourdieu, 2006) ${ }^{32}$.

AN impone su visión sobre la población indígena y construye una versión de la identidad mapuche, que será la que ofrezca al público. De cara al turismo, entonces, la actividad artesanal de la comunidad remite a la producción de un pueblo originario, fijada como producto étnico y exótico, anclada en el pasado, pero con potencialidades para desarrollar toda transformación que el mercado requiera en pos de tornar factible su venta.

En la misma línea y atendiendo a las características que guardan algunos productos — básicamente aquellos en madera—, será la comercialización la que en gran medida los individualizará y tipificará o no, como bienes "representativos" de un grupo étnico. Así sucede positivamente en ferias y encuentros con participación exclusiva o manifiesta de pobladores mapuches y en algunos comercios; excluyentemente en la mayoría de locales comerciales y en ferias y eventos de convocatoria amplia y heterogénea, donde la adscripción étnica de los productores mapuches no se halla explicitada y/o sus artículos se encuentran diluidos en un universo artesanal indiferenciado.

\section{Consideraciones finales}

Nos ha interesado hasta aquí desnaturalizar la concepción de las producciones artesanales de los pueblos originarios en su atribución de piezas dilectas de expresión identitaria.

En primer lugar, señalamos que los artículos — con sus procesos de trabajo respectivos, más las prácticas y representaciones de los sujetos en torno a la actividad- no pueden considerarse una totalidad indiferenciada. No todas las producciones guardan similares características.

La apreciación de la actividad artesanal como recurso con valor — simbólicoconstitutivo de la memoria y la identidad étnica para las comunidades, resulta acotada.

Hace a este proceso, el reconocimiento otorgado al bien en cuestión. En este sentido, los bienes artesanales reconocidos y representativos se orientan hacia los tejidos y las piezas en plata ${ }^{33}$; los artículos en madera no son objeto del mismo registro.

${ }^{32}$ Las luchas por la identidad étnica son un caso particular de las luchas por las clasificaciones, "luchas por el monopolio del poder de hacer ver y de hacer creer, de hacer conocer y de hacer reconocer, de imponer la definición legítima de las divisiones del mundo social y, por ello, de hacer y de deshacer los grupos: estas luchas tienen en efecto por apuesta el poder de imponer una visión del mundo social" (Bourdieu, 2006).

${ }^{33}$ La producción en plata presenta aspectos sumamente interesantes para la problemática abordada. No obstante, por cuestiones de espacio, no ha sido objeto de tratamiento en este trabajo. 
Los textiles son legitimados por sus productoras y estimados como constitutivos de su identidad étnica. Se reconocen en ellos y éstos se asocian a valores emblemáticos, situados en el pasado y recuperados para valorizar el presente.

Sobre las piezas en madera, los saberes, la práctica y los objetos se asocian estrechamente con una opción laboral; la actividad es recuperada y estimada más como fuente posible de ingresos, que en su condición de labor tradicional — que pasa a un segundo plano o directamente se desvanece-.

En cada caso específico, en las distintas comunidades, los valores identitarios se conjugan diferencialmente respecto de los requerimientos económicos. Cabe agregar que, si bien la categoría "trabajo" impregna la producción artesanal en general, en el caso de la tarea en madera se podría sugerir que directamente la subsume.

En segundo lugar, planteamos que en la actividad artesanal los procesos de legitimación no se limitan al ámbito productivo y se desarrollan además con intervención de agentes externos a las comunidades.

La "legitimidad" que se confiere a los tejidos —en tanto productos étnicamente representativos - es asignada por las artesanas a los artículos y a la actividad. El reconocimiento se asocia al espacio productivo, independientemente de la faz de comercialización ${ }^{34}$.

En los productos en madera, difícilmente se da tal identificación de los pobladores con el espacio de la producción - inciden en tal apreciación los factores ya mencionados de: características de las piezas, tipos de saberes involucrados, grado de reconocimiento comunitario de la actividad, etc.- - La legitimación se producirá en el ámbito de expendio, pero no por los productores sino por los diferentes actores que intervienen en el campo de la comercialización. En este sentido, el reconocimiento de la producción artesanal mapuche también se arbitra en la instancia de venta.

Puede pensarse a ésta última como espacio que potencialmente habilita contenidos identitarios en determinados bienes, al dar cuenta de que la posibilidad de ciertos productos de ser "identificados" como mapuches se concreta o diluye según el sitio donde se expenden.

Además, los agentes externos a las comunidades proceden no sólo fijando las reglas bajo las cuales se realizarán las operaciones comerciales, sino que operan como entes con poder reformulador y decisorio sobre las características de la producción artesanal.

Entendemos que los procesos analizados son factibles de comprenderse desde una perspectiva no sustancialista, que entiende que las identidades étnicas se conforman a partir de procesos históricos específicos, que incluyen fenómenos de permanencia y cambio y que en tal contexto las producciones artesanales se dinamizan y expresan en ellas las características que asumen las condiciones de vida de los pueblos originarios, así como las problemáticas y tensiones implícitas en su relación con la sociedad global desde una condición de subalternidad.

${ }^{34}$ No obstante, como ya señaláramos, en el caso del Taller de Chiuquilihuín, dadas sus características, tal instancia de venta contribuye a reforzar la condición adjudicada. 


\section{Referencias bibliográficas}

BALAZOTE, Alejandro

1999 "Relaciones entre capital y trabajo en grupos mapuche de Norpatagonia", en S. Narotzky, J. A. Galván Tudela, U. Martinez Veiga (coords.), Antropología y Economía Política. Santiago de Compostela: FAAEE-AGA, 37-47.

BALAZOTE, Alejandro; RADOVICH, Juan Carlos

1992 "El concepto de Grupo Doméstico", en H. H. Trinchero (comp.), Antropología Económica II. Conceptos Fundamentales. Buenos Aires: Centro Editor de América Latina, 27-43.

BARTOLOME, Miguel

2006 Procesos Interculturales. Antropología Política del pluralismo cultural en América Latina. México: Siglo XXI Editores.

BELAUSTEGUI, Silvina; CASTAÑEDA, Sara; LAZOS, Cristina; et. al.

1999 Corredor de los Lagos del Sur del Neuquén. Informe Final: Neuquén: Fundación de Estudios Patagónicos-Copade.

BONFIL BATALLA, Guillermo

1992 Identidad y pluralismo cultural en América Latina. Buenos Aires, San Juan: Fondo Editorial del CEHASS, Editorial de la Universidad de Puerto Rico

BOURDIEU, Pierre

2006 "La identidad y la representación: elementos para una reflexión crítica sobre la idea de región”. Ecuador Debate, 67: 165-184.

CARPINETTI, Bruno

2005 Derechos Indígenas en el Parque Nacional Lanin. De la expulsión al co-manejo. Buenos Aires: Administración de Parques Nacionales.

CONEJEROS, Ruth

2004 "Divinidades en el arte textil del Puel Mapu (Tierra del Este)", en A.M. Lamazares, C. Martinez Sarasola (eds.), El lenguaje de los dioses. Buenos Aires: Biblos, 199-226.

ESPÓSITO, Maria

2004 Arte Mapuche. Buenos Aires: Editorial Guadal.

ESPÓSITO, Patricia

2005 El circuito de la madera en las Comunidades Mapuche de Chiuquilihuin y Aucapan. Proyecto Mapuche-Pehuenche. Desarrollo Sustentable para las Comunidades indígenas de Chiuquilihuin y Aucapan.

FALASCHI, Carlos

1994 La Confederación Indígena Neuquina. Serie La Tierra Indígena Americana. Vol. 4. Neuquén: I.R.E.P.S.- A.P.D.H. 
GALLO, Leonardo; IZQUIERDO, Fernanda

2002 Conservación, manejo y uso sustentable de los recursos genéticos de Araucaria araucana en Argentina. Proyecto Pehuén. IPGRI-BMZ-INTA-APN-AUSMA de Pcia de Neuquén, Bariloche.

GARCIA, Analia

2007 "Diversificación económica y planes de gobierno en los departamentos del sur de la provincia de Neuquén. El caso de los departamentos Lácar y Huiliches”, en M. Rotman, J. C. Radovich y A. Balazote (eds.), Pueblos originarios y problemática artesanal: Procesos productivos y de comercialización en agrupaciones Mapuches, Guaranies/Chané, Wichí, Quom/Toba y Mocoviés. Córdoba: CONICET-Centro de Estudios Avanzados de la Universidad Nacional de Córdoba, 19-40.

\section{GARCÍA CANCLINI, Néstor}

1982 Las Culturas Populares en el capitalismo. México: Editorial Nueva Imagen.

\section{GIMÉNEZ, Gilberto}

2000 "Identidades Étnicas: Estado de la cuestión”, en L. Reina (coord.), Los retos de la etnicidad en los estados-nación del siglo XXI. México: Centro de Investigaciones y Estudios Superiores en Antropología Social-Instituto Nacional Indigenista-Miguel Ángel Porrúa., 45-70.

INDEC

2004-2005 Encuesta Complementaria de Pueblos Indígenas (ECPI) 2004-2005 [Complementa el Censo de Población de 2001].

MANAZZA, José

1994 "Proyecto de desarrollo rural integral para reservas indígenas del sur de Neuquén. Reconversión Ganadero Forestal y Producción de Alimentos”. Presencia, Año IX, 31: 24-35. Revista del INTA Bariloche.

NOVELO, Victoria

1976 Artesanias y Capitalismo en México. México: SEPH-INAH.

1981 "Para el estudio de las Artesanías mexicanas". América Indígena, vol. XLI, 2: 99-118.

1993 "Las artesanías en México", en E. Florescano (comp.), El patrimonio cultural de México. México: FCE, 219-246.

PERALTA, Carlos

2003a Informe del sondeo de descripción cualitativa de la comunidad de Chiuquilihuín. Informe técnico. Neuquén: ONG Recerca e Cooperazione. Mimeografía.

2003b Sondeo de descripción cualitativa comunidad de Aucapán. Informe técnico. Neuquén: ONG Recerca e Cooperazione. Mimeografía.

PÉREZ RAVENTÓS, Alicia

2003 Una nueva relación en el Parque Nacional Lanín: El Comité de Gestión del CoManejo con "determinació" Mapuche. CLASPO, Proyecto Comparado sobre Políticas Públicas. Neuquén Subred-Indígena. Informe de Investigación. http:// lanic.utexas.edu/project/etext/llilas/claspo/rtc/0011.pdf. 


\section{PROYECTO PEHUENCHE}

2002 Desarrollo sustentable para las comunidades indígenas de Chiuquilihuín y Aucapan-Argentina. Proyecto-Documento Interno. Neuquén: ONG Recerca e Cooperazione-INTA. Mimeografía. [No se explicita autoría].

RADOVICH, Juan Carlos; BALAZOTE, Alejandro

1995 "Transiciones y fronteras agropecuarias en Norpatagonia", en H. Trinchero (ed.), Producción doméstica y capital. Estudios desde la Antropología Económica. Buenos Aires: Biblos, 63-80.

ROTMAN, Mónica

2007a "Prácticas artesanales: Procesos Productivos y reproducción social en la Comunidad Mapuche Curruhuinca", en M. Rotman, J. C. Radovich y A. Balazote (eds.), Pueblos originarios y problemática artesanal: Procesos productivos y de comercialización en agrupaciones Mapuches, Guaranies/Chané, Wichí, Quom/Toba y Mocoviés. Córdoba: CONICET-CEA, Universidad Nacional de Córdoba, 41-69.

2007b Producciones artesanales y procesos de patrimonialización: un estudio de caso en comunidades Mapuche de la Pcia. de Neuquén. Disertación presentada en el XI Coloquio de Antropología Social "Políticas culturales, patrimonio y participacion ciudadana", ICA-FFyL-UBA.

\section{SECRETARÍA DE MINERÍA DE LA NACIÓN-REPÚBLICA ARGENTINA}

2007 Página web. http://www.mineria.gov.ar/ambiente/estudios/IRN/neuquen

STECHER, Gabriel

2007 "El bosque y la actividad forestal en las comunidades mapuche Atreico, Aucapán y Chiuquilihuín (Dto. Huiliches-Neuquén)”, en M. Rotman, J. C. Radovich y A. Balazote (eds.), Pueblos originarios y problemática artesanal:Procesos productivos y de comercialización en agrupaciones Mapuches, Guaranies/Chané, Wichí, Quom/Toba y Mocoviés. Córdoba: CONICET-CEA, Universidad Nacional de Córdoba,127-145.

\section{SUBSECRETARÍA DE TURISMO DE NEUQUÉN}

s. a. Planillas de Datos. Dirección Provincial de Estadísticas y Censos. Provincia de Neuquén.

2008 Pagina web. www.neuquentur.gov.ar- 